\title{
CANABIDIOL E SUAS APLICAÇÕES TERAPÊUTICAS
}

\author{
CANNABIDIOL AND ITS THERAPEUTIC APPLICATIONS \\ ${ }^{1,2}$ Érika Cardoso Gontijo; ${ }^{1}$ Geysilla Lorrany Castro; ${ }^{3}$ Anamaria Donato de Castro \\ Petito; ${ }^{3}$ Guilherme Petito
}

\begin{abstract}
RESUMO
Introdução: Atualmente sabe-se que a Cannabis sativa, popularmente conhecida como maconha, apresenta substâncias com promissoras propriedades farmacológicas. Dentre estas destaca-se o canabidiol (CBD), que vem mostrando potencial efeito no tratamento de diversas doenças, como: autismo, epilepsia, ansiedade e outras. Objetivo: Evidenciar a importância do estudo sobre o CBD, mostrando como essa substância apresenta efeitos promissores, para tratamento de várias doenças graves. Método: Trata-se de uma revisão da literatura, exploratória, de aspecto qualitativo, realizada por meio de busca ativa nas bases de dados do SCIELO, LILACS e da BIREME, utilizando como ferramenta de busca o site Periódicos Capes, utilizando as seguintes palavras-chave: . sativa; Fitocanabinóides; Uso terapêutico. Resultados: Medicamentos com alto teor de CBD já vem sendo utilizado, em alguns países, inclusive no Brasil, em pacientes que sofrem severas crises convulsivas, até mesmo em pacientes infantis, apresentando bons resultados e poucos efeitos colaterais. No Brasil, com a autorização da Agência Nacional de Vigilância (ANVISA) já se pode importar extratos padronizados produzidos por indústrias farmacêuticas internacionais. Contudo, o processo ainda é burocrático. Além de ser usado no tratamento de epilepsia o CBD, se mostra promissor também no tratamento de outras doenças como ansiedade, doenças neurodegenerativas, esclerose múltipla e dor neuropática. Conclusão: As propriedades terapêuticas do CBD merecem atenção especial, devendo ser realizadas mais pesquisas para maior conhecimento dessa substância e consequentemente, conhecer melhor seu mecanismo de ação no tratamento de doenças.
\end{abstract}

Palavras-Chave: Cannabis sativa; Fitocanabinóides; Uso terapêutico.

\begin{abstract}
\footnotetext{
${ }^{1}$ Acadêmica do Curso de Farmácia, FACER - Faculdades Unidade de Ceres-GO.

${ }^{2}$ Autor correspondente: eriikagontijo@live.com

${ }^{3}$ Docente da FACER - Faculdades Unidade de Ceres-GO.

Data do recebimento: 10/02/2016

Data da aprovação: 08/04/2016
}

Introduction: It is currently known that Cannabis sativa, popularly called marijuana, has substances with promising pharmacological properties. Among which cannabidiol (CBD) stands out, since it has shown a potential effect in the treatment of many kinds of illnesses, such as autism, epilepsy, anxiety and many others. Objective: To highlight the importance of studying CDB, understanding how it could be promising in the treatment of several serious diseases. Method: This is a methodical literature review, but also exploratory, and of qualitative aspect, carried out through searches using databases such as SCIELO, LILACS and BIREME, having Periódicos Capes as the search engine platform, making use of the keywords: C. sativa, Phytocannabinoids, Therapeutic role. Results: Drugs with high CBD percentage are already being use in some countries, including Brazil, in patients undergoing severe seizures, even in pediatric patients, with fair results and few side effects. 
In Brazil, with the allowance of the National Surveillance Agency (ANVISA) it is possible to import standardizes extracts produced by international pharmaceutical companies. However, it is still a bureaucratic process. Besides its use in the treatment of epilepsy, CBD has also shown potential against diseases such as anxiety, neurodegenerative disorders, multiple sclerosis and neuropathic pain. Conclusion: The therapeutic properties of CDB deserve special attention and there should be more researches in order to acquire more knowledge about its possible role in the treatment of other diseases.

Keywords: Cannabis sativa; Phytocannabinoids; Therapeutic role.

\section{INTRODUÇÃO}

A Cannabis Sativa, popularmente conhecida no Brasil como maconha, é uma erva, originada na Ásia Central e que possui grande adaptabilidade no que se refere ao clima, altitude e solo (COUTINHO; ARAÚJO; GONTIÉS, 2004). Essa planta apresenta diversas propriedades que podem ser usadas de forma hedonistas, industriais e terapêuticas (BRANDÃO, 2014).

Há relatos do uso medicinal da C. sativa, na farmacopeia chinesa, a mais antiga do mundo, onde nela é descrito o uso da erva no tratamento de várias doenças como, dores reumáticas, distúrbios intestinais, malária e problemas no sistema reprodutor feminino. $\mathrm{Na}$ Índia há relatos do uso da $C$. sativa, no tratamento de insônia, febre, tosse seca e disenteria (RIBEIRO, 2014; CRIPPA; ZUARDI; HALLAK, 2010).

No início da década de 60 foram isolados os principais componentes da $C$. sativa, entre eles destacam-se o $\Delta$ 9-tetraidrocanabinol ( $\Delta$ 9-THC) e o Canabidiol (CBD). Até agora são conhecidos mais de 80 canabinoides (ZUARDI; CRIPPA; HALLAK,2010). O interesse sobre o CBD aumentou significantemente, pois cada vez mais seus possíveis efeitos terapêuticos ficam em evidência (DE MELO et al., 2012).

O presente estudo teve como objetivo, evidenciar a ampla aplicabilidade do CBD no tratamento de algumas doenças.

\section{METODOLOGIA}

Trata-se de uma revisão da literatura, descritivo, de aspecto qualitativo, por meio de busca ativa nas bases de dados do SCIELO, LILACS e da BIREME, utilizando como ferramenta de busca os sites Periódicos Capes, associando o descritor Canabidiol às palavras chave: Uso terapêutico; Fitocanabinóides; C. sativa. Foram incluídos artigos completos, em língua portuguesa, pertencentes às bases de dados SCIELO, LILACS e BIREME, publicados 
entre 2004 a 2015. Artigos pagos, artigos não associados ao tema e as duplicações de indexação de artigos foram excluídos.

\section{REVISÃO BIBLIOGRÁFICA}

\section{SISTEMA ENDOCANABINÓIDE}

As investigações sobre o mecanismo de ação do $\Delta 9$-THC, levou a descoberta de um receptor canabinóide no sistema nervoso central, denominado canabinóide 1 (CB1) (DA COSTA et al., 2014). O CB1 é principalmente encontrado em nível do sistema nervoso central e medeia os efeitos psicotrópicos dos canabinóides. Após a caracterização molecular deste receptor, foi descoberto o primeiro endocanabinóide (ligante endógeno capaz de ativar os receptores canabinódes), a anandamida (AEA). Após a descoberta do receptor CB1 no sistema nervoso central, um outro receptor foi identificado e chamado de canabinóide 2 (CB2), localizado principalmente em órgãos e tecidos periféricos. Outros endocanabinóides também foram encontrados como o 2- araquidonilglicerol (2-AG), a virodamina e outros (FONSECA et al., 2013).

Há também ligantes sintéticos que atuam como agonistas nesse receptor, e que são de grande importância para estudos farmacológicos, como o WIN-55. Além disso, antagonistas seletivos foram desenvolvidos, um exemplo é o SR141716 (rimonabanto), o qual é capaz de bloquear os efeitos da maconha em humanos (DA COSTA et al., 2014).

Assim, o Sistema Endocanabinóide (Figura 1) é constituído pelos receptores canabinóides, pelos endocanabinóides, pelas enzimas envolvidas no seu metabolismo e pelo respectivo transportador membranar (FONSECA et al., 2013).

O CBD, substância a qual daremos enfoque neste estudo, não apresenta afinidade significativa pelo receptor CB1, alguns dos seus efeitos, como o ansiolítico, parecem ser mediados pelo receptor serotoninérgico 5-HT1A. Assim, pelo menos dois sistemas de neurotransmissores parecem estar envolvidos com a gama de efeitos gerados pela C. sativa, o sistema endocanabinóide e o serotoninérgico (DA COSTA et al., 2014). 


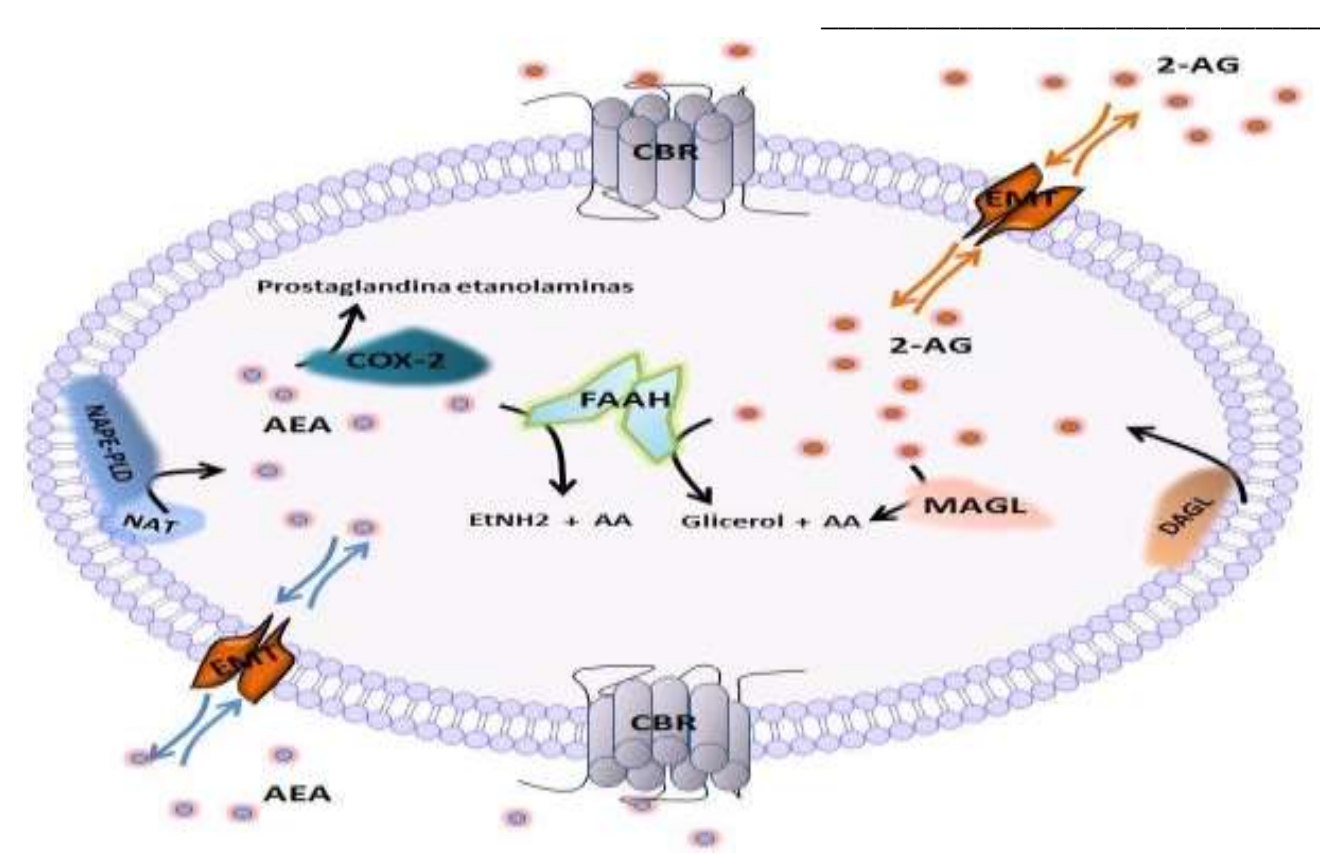

Figura 1. Representação esquemática do Sistema Endocanabinóide. Fonte: FONSECA et al., 2013.

\section{CANABINÓIDE (CBD)}

O CBD é um composto encontrado em grande quantidade na $C$. sativa, constituindo cerca de $40 \%$ O CBD foi isolado no início da década de 40, porém sua estrutura química foi esclarecida apenas na década de 60 (figura 2) (PEDRAZZI et al., 2014).

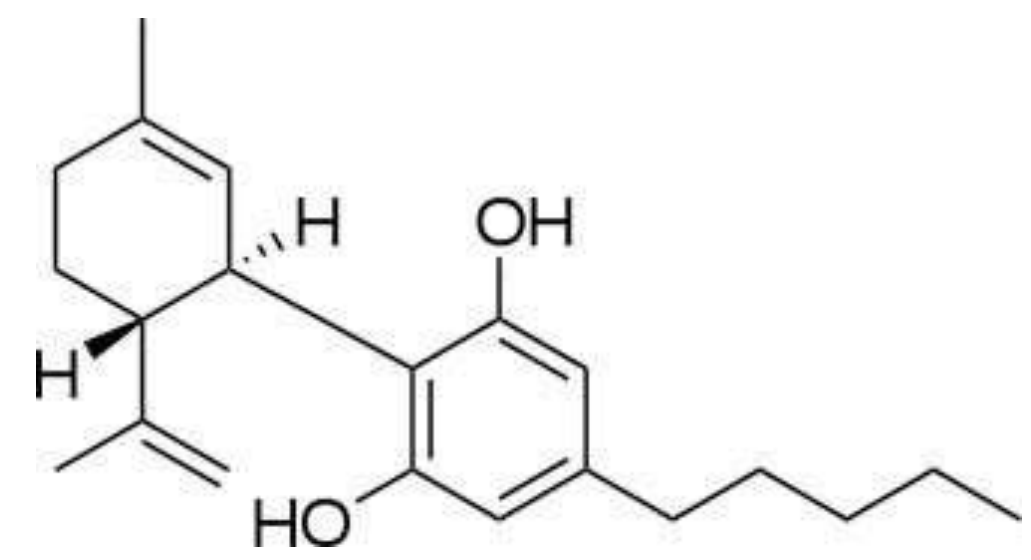

Figura 2: Estrutura química CBD. Fonte: FONSECA et al., 2013.

\section{USO DO CBD NO TRATAMENTO DE DOENÇAS}

\section{EPILEPSIA}

Pacientes epilépticos são refratários ao tratamento com medicamentos anticonvulsivantes, até mesmo quando o médico escolhe a terapêutica correta utilizando doses adequadas e toleradas pelo paciente. Quando as crises epiléticas não são controladas pioram a qualidade de vida do paciente, e são associadas à comorbidades médicas, psicossociais e cognitivas (BRAGATTI, 2015). 
O primeiro relato do uso de CBD, no tratamento de convulsão, foi publicado no dia 4 de fevereiro de 1843 pelo médico irlandês William Brook O’Shaughnessy. Relatando o caso de uma menina indiana com quarenta dias de vida que sofria crises severas de convulsões, as quais não respondiam a nenhum tipo de tratamento aplicado na época, como purgativos e opióides. O’Shaughnessy deu a primeira gota de tintura de resina de Cannabis indica, que equivalia cerca de $3 \mathrm{mg}$ de resina. Imediatamente nada foi observado, então uma hora e meia depois mais duas gotas foram dadas, ás 23:00 horas. Em poucos minutos a menina caiu em um sono profundo, acordando apenas ás 16:00 horas do dia seguinte. Permanecendo sem convulsões durante quatro dias. No quinto dia as convulsões retornaram, o tratamento foi retomado então com uma tintura fresca, porém não havia efeito com doses aplicadas de até 8 gotas, decidiram dar uma única dose de 30 gotas, o que resultou na interrupção das convulsões e em um sono profundo de treze horas. Não está claro no relato o tempo em que o tratamento continuou, mais em sua última descrição O'Shaughnessy descreve a menina com perfeita saúde e alegria, levando a entender que as convulsões não retornaram (MALCHER-LOPES, 2014).

Atualmente temos outros relatos de casos parecidos com o da menina indiana de O'Shaughnessy. No âmbito internacional foi mostrado o caso de Charlotte Figi, uma menina de cinco anos que sofre de síndrome de Dravet, mostrado no documentário "Weed" da rede TV CNN. Já no Brasil o quadro “'Ilegal' mostrou o caso de Anny Fischer, uma menina de seis anos que sofre de síndrome de CDKL5. Ambas as síndromes são caracterizadas por crises epiléticas severas e regressão autística. Os pais de ambas as crianças, resolveram tratálas com óleo extraído de variedades de C. sativa ricas em CBD e com baixa concentração de tetrahidrocanabinol (THC). Os resultados foram ótimos, reduzindo quase totalmente as convulsões e melhorando os sintomas autísticos, sendo o único efeito colateral observado a sonolência (MALCHER-LOPES, 2014).

\section{ANSIEDADE}

Pesquisas realizadas com CBD mostram que esse fitocanabinóide apresenta efeitos ansiolíticos consistentes (DA COSTA et al., 2014). Aparentemente tais efeitos, são parecidos com os dos medicamentos aprovados para tratar ansiedade, porém suas doses ainda não são bem estabelecidas e seus mecanismos de ação não são totalmente compreendidos (DE MELLO SCHIER et al., 2012). 


\section{DOENÇAS NEURODEGENERATIVAS}

Segundo estudos realizados em roedores o CBD tem-se mostrado, bastante eficaz no tratamento de doenças neurodegenerativas, como Doença de Parkinson, apresentando propriedades antioxidantes e neuroprotetoras (SILVA, 2013).

Foi realizado um estudo, testando a administração de CBD em seis pacientes ambulatoriais, diagnosticados com doença de Parkinson e com sintomas psicóticos associados por pelo menos três meses. Eles receberam uma dose oral de CBD começando por $150 \mathrm{mg} /$ dia durante quatro semanas, além de suas terapias usuais. O Tratamento com o CBD reduziu significativamente tanto os sintomas psicóticos como os motores e não houve nenhuma piora dos sintomas cognitivos. Com esses resultados preliminares constatou que o CBD pode ter efeitos positivos na doença de Parkinson. Um dos primeiros efeitos observados com o uso do CBD foi sua ação sedativa, e assim verificou que em pacientes com doenças de Parkinson relataram a melhora da qualidade do sono, o que é um problema comum neste transtorno de movimentos (CRIPPA; ZUARDI; HALLAK, 2010).

\section{ESCLEROSE MÚLTIPLA}

A Esclerose Múltipla é a doença neurologicamente progressiva e incapacitante mais comum entre adultos jovens (DA SILVA, 2013).

O uso de componentes da $C$. sativa é muito discutido no tratamento sintomático e preventivo dessa doença. Em alguns países o medicamento naxibimol, é indicado para espasticidade na Esclerose Múltipla, ele contém THC e CBD, na proporção de 1:1, este medicamento é exclusivamente de uso oro-bucal. Para indicação de uso de canabinóides no tratamento de espasticidade, deve se tomar certa precaução, pois seus efeitos adversos podem ser agravados em função de características inerentes a doença, sintomas como comprometimento cognitivo, fadiga e alterações no humor, que podem variar de depressão à ideação suicida (BRUCK et al., 2015)

\section{DOR NEUROPÁTICA}

Foram avaliados três estudos na eficácia da $C$. sativa no tratamento de dor neuropática. Em um dos estudos foram utilizados a forma de spray, como analgésico adjuvante no tratamento de dor central em pacientes com esclerose múltipla. No outro estudo foi utilizado na forma inalatória, com dor neuropática pós-traumática ou pós- cirúrgica, 
observando melhoras na intensidade da dor. E no último estudo observaram melhora da dor neuropática em pacientes com imunodeficiência humana HIV (BRUCK et al., 2015).

O laboratório britânico GW Pharmaceuticals foi o primeiro a obter medicação diretamente da planta $C$. sativa, a partir dos princípios ativos $\Delta 9$ - THC e o CBD. Foram realizados testes clínicos que foram aprovados, para que médicos prescrevessem, permitindo doses individualizadas em spray oral (Sativex $\left.{ }^{\circledR}\right)$, de acordo com a resposta do próprio paciente. Pacientes com dor neuropática fazem média de 8 a 12 aplicações de spray por dia, consumindo cerca de 2,5 mg (20 a $30 \mathrm{mg}$ por dia) de CBD e 2,7 mg de (22 a $32 \mathrm{mg}$ por dia) $\Delta 9$-THC. No Canadá esse medicamento já é comercializado, onde seu uso já é aprovado (BONFÁ; VINAGRE; FIGUEIREDO, 2008).

\section{LIBERAÇÃO DO CBD NO BRASIL}

Apesar de existir ainda, muita resistência por parte de organizações médicas tradicionais, alguns países já legalizaram o uso da maconha, seja para fins medicinais ou até mesmo recreativos. Uruguai e Argentina são alguns exemplos na América do Sul, os Estados Unidos, que liderava campanhas para proibição, hoje aceita o uso medicinal em diversos estados e o uso recreativo em pelo menos dois estados (PAMPLONA, 2014).

Em 2015, no Brasil a Agência Nacional de Vigilância Sanitária (ANVISA), autorizou a importação do CBD. Apesar da liberação, o preço elevado da importação torna essa substância inacessível para a maior parte da população (BENTES, 2015).

\section{CONSIDERAÇÕES FINAIS}

A presente revisão revela a ampla aplicabilidade do CBD no tratamento de algumas doenças, demonstrando o potencial terapêutico desta substância no tratamento de doenças que atingem o sistema nervoso e a importância da realização de estudos e experimentos que permitam ampliar o conhecimento, tanto de sua ação como dos seus efeitos colaterais.

A liberação da $C$. sativa, para fins medicinais e de pesquisas, é de grande importância, uma vez que evidenciado o potencial farmacológico de alguns de seus princípios ativos, estudos acerca destas substâncias definiriam melhores estratégias de uso, tanto em relação à dose quanto à frequência e cuidados acerca de possíveis reações.

\section{REFERÊNCIAS}

BENTES, I. "Ponham as cartas na mesa e discutam essas leis": a luta pela legalização da maconha no Brasil. Argumentum, v. 7, n. 1, p. 93-107, 2015 
BONFÁ, L.; VINAGRE, R.C.O.; FIGUEIREDO, N.V. Uso de canabinóides na dor crônica e em cuidados paliativos. Rev Bras Anestesiol, v. 58, p. 267-279, 2008.

BRAGATTI, J.A. O Uso do Canabidiol em Pacientes com Epilepsia, 2015. BRANDÃO, M.D. Ciclos de atenção à maconha no Brasil. Rev. da Biologia, v. 13, n.

1, p. 1-10, 2014.

BRUCKI, S. et al. Cannabinoids in neurology-Brazilian Academy of Neurology. Arquivos de neuro-psiquiatria, v. 73, n. 4, p. 371-374, 2015.

COUTINHO, M.P.L.; ARAÚJO, L.F.; GONTIÈS, B. Uso da maconha e suas representações sociais: estudo comparativo entre universitários. Psicologia em estudo, v. 9, n. 3, p. 469-477, 2004.

CRIPPA, J.A.S. et al. Uso terapêutico dos canabinoides em psiquiatria. Rev. Brasileira de Psiquiatria, v. 32, n. suppl 1, p. 556-566, 2010.

DA SILVA, T.V. Avaliação dos efeitos do canabidiol sobre os eventos imunológicos e degenerativos induzidos pela encefalomielite autoimune experimental (EAE) em camundongos. 2013.

DA COSTA, L.A. et al. Aspecto dual da maconha na ansiedade e no humor. Rev. da Biologia, v. 13, n. 1, p. 36-42, 2014.

DE MELLO SCHIER, A.R. et al. Canabidiol, um componente da Cannabis sativa, como um ansiolítico. Official Journal of the Brazilian Psychiatric Association, v. 34, p. 1, 2012.

DUARTE, C. O Potencial Analgésico dos Canabinóides, 2012.

FONSECA, B.M. et al. O Sistema Endocanabinóide-uma perspetiva terapêutica. Acta Farmacêutica Portuguesa, v. 2, n. 2, p. 37-44, 2013.

MALCHER-LOPES, R. Canabinoides ajudam a desvendar aspectos etiológicos em comum e trazem esperança para o tratamento de autismo e epilepsia. Rev. da Biologia, v. 13, n. 1, p. 43-59, 2014.

PAMPLONA, F.A, Quais são e pra que servem os medicamentos à base de Cannabis?. Rev. da Biologia, v. 13, n. 1, p. 28-35, 2014.

PEDRAZZI, J.F.C. et al. Perfil antipsicótico do canabidiol. Medicina (Ribeirao Preto. Online), v. 47, n. 2, p. 112-119, 2014.

RIBEIRO, J.A.C.; A cannabis e suas aplicações terapêuticas, 2014.

SILVA, V.K. da. Alterações das proteínas de fissão e fusão mitocondriais, caspase 3 e sinaptofisina cerebrais induzidas pela sobrecarga de ferro neonatal: reversão pelo tratamento com canabidiol, 2013. 
ZUARDI, A.W.; CRIPPA, J.A.S.; HALLAK, J.E.C. Cannabis sativa: a planta que pode produzir efeitos indesejáveis e também tratá-los:[editorial]. Rev. bras. Psiquiatria, v.32, n. supl. 1, p. 51-52, 2010. 